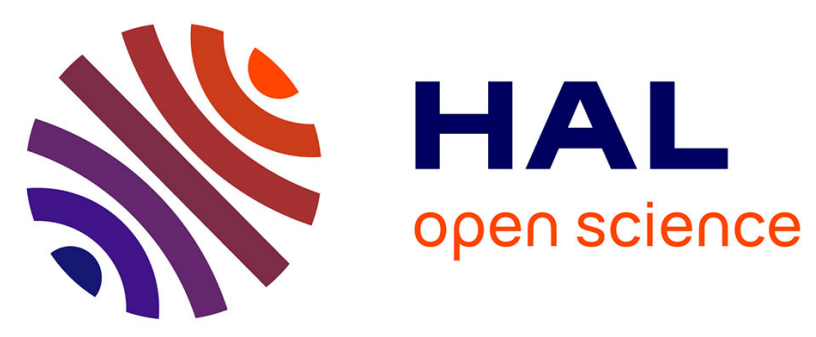

\title{
Contrasting associations between nestling telomere length and pre and postnatal helpers' presence in a cooperatively breeding bird
}

Martin Quque, Matthieu Paquet, Sandrine Zahn, Franck Théron, Bruno

Faivre, Cedric Sueur, François Criscuolo, Claire Doutrelant, Rita Covas

\section{To cite this version:}

Martin Quque, Matthieu Paquet, Sandrine Zahn, Franck Théron, Bruno Faivre, et al.. Contrasting associations between nestling telomere length and pre and postnatal helpers' presence in a cooperatively breeding bird. Oecologia, 2021, 10.1007/s00442-021-04917-8 . hal-03204550

\section{HAL Id: hal-03204550 \\ https://hal.science/hal-03204550}

Submitted on 21 Apr 2021

HAL is a multi-disciplinary open access archive for the deposit and dissemination of scientific research documents, whether they are published or not. The documents may come from teaching and research institutions in France or abroad, or from public or private research centers.
L'archive ouverte pluridisciplinaire HAL, est destinée au dépôt et à la diffusion de documents scientifiques de niveau recherche, publiés ou non, émanant des établissements d'enseignement et de recherche français ou étrangers, des laboratoires publics ou privés. 
Dear Author,

Here are the proofs of your article.

- You can submit your corrections online, via e-mail or by fax.

- For online submission please insert your corrections in the online correction form. Always indicate the line number to which the correction refers.

- You can also insert your corrections in the proof PDF and email the annotated PDF.

- For fax submission, please ensure that your corrections are clearly legible. Use a fine black pen and write the correction in the margin, not too close to the edge of the page.

- Remember to note the journal title, article number, and your name when sending your response via e-mail or fax.

- Check the metadata sheet to make sure that the header information, especially author names and the corresponding affiliations are correctly shown.

- Check the questions that may have arisen during copy editing and insert your answers/ corrections.

- Check that the text is complete and that all figures, tables and their legends are included. Also check the accuracy of special characters, equations, and electronic supplementary material if applicable. If necessary refer to the Edited manuscript.

- The publication of inaccurate data such as dosages and units can have serious consequences. Please take particular care that all such details are correct.

- Please do not make changes that involve only matters of style. We have generally introduced forms that follow the journal's style.

Substantial changes in content, e.g., new results, corrected values, title and authorship are not allowed without the approval of the responsible editor. In such a case, please contact the Editorial Office and return his/her consent together with the proof.

- If we do not receive your corrections within $\mathbf{4 8}$ hours, we will send you a reminder.

- Your article will be published Online First approximately one week after receipt of your corrected proofs. This is the official first publication citable with the DOI. Further changes are, therefore, not possible.

- The printed version will follow in a forthcoming issue.

\section{Please note}

After online publication, subscribers (personal/institutional) to this journal will have access to the complete article via the DOI using the URL: http://dx.doi.org/[DOI].

If you would like to know when your article has been published online, take advantage of our free alert service. For registration and further information go to: http://www.link.springer.com.

Due to the electronic nature of the procedure, the manuscript and the original figures will only be returned to you on special request. When you return your corrections, please inform us if you would like to have these documents returned. 


\section{Metadata of the article that will be visualized in OnlineFirst}

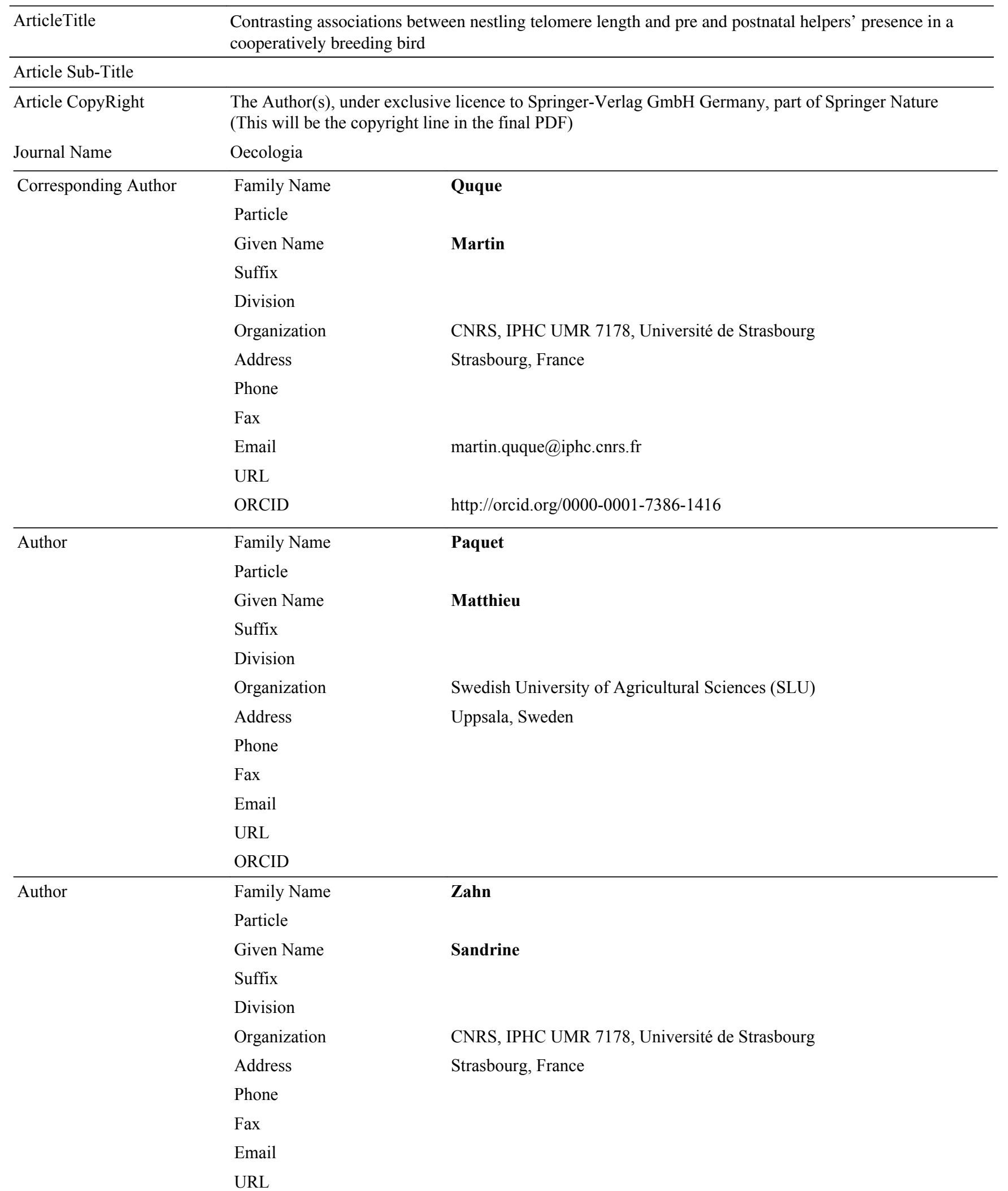


ORCID

\begin{tabular}{|c|c|c|}
\hline \multirow[t]{12}{*}{ Author } & Family Name & Théron \\
\hline & Particle & \\
\hline & Given Name & Frank \\
\hline & Suffix & \\
\hline & Division & \\
\hline & Organization & CNRS, CEFE UMR 5175, Université de Montpellier \\
\hline & Address & Montpellier, France \\
\hline & Phone & \\
\hline & Fax & \\
\hline & Email & \\
\hline & URL & \\
\hline & ORCID & \\
\hline \multirow[t]{12}{*}{ Author } & Family Name & Faivre \\
\hline & Particle & \\
\hline & Given Name & Bruno \\
\hline & Suffix & \\
\hline & Division & Biogéosciences \\
\hline & Organization & CNRS UMR 6282, Université de Bourgogne Franche-Comté \\
\hline & Address & Dijon, France \\
\hline & Phone & \\
\hline & Fax & \\
\hline & Email & \\
\hline & URL & \\
\hline & ORCID & \\
\hline \multirow[t]{15}{*}{ Author } & Family Name & Sueur \\
\hline & Particle & \\
\hline & Given Name & Cédric \\
\hline & Suffix & \\
\hline & Division & \\
\hline & Organization & CNRS, IPHC UMR 7178, Université de Strasbourg \\
\hline & Address & Strasbourg, France \\
\hline & Division & \\
\hline & Organization & Institut Universitaire de France \\
\hline & Address & Paris, France \\
\hline & Phone & \\
\hline & Fax & \\
\hline & Email & \\
\hline & URL & \\
\hline & ORCID & \\
\hline \multirow[t]{5}{*}{ Author } & Family Name & Criscuolo \\
\hline & Particle & \\
\hline & Given Name & François \\
\hline & Suffix & \\
\hline & Division & \\
\hline
\end{tabular}


Organization

Address

Phone

Fax

Email

URL

ORCID

\begin{tabular}{|c|c|c|}
\hline & \multicolumn{2}{|l|}{$\operatorname{Fax}$} \\
\hline & Email & \\
\hline & URL & \\
\hline & ORCID & \\
\hline \multirow[t]{15}{*}{ Author } & Family Name & Doutrelant \\
\hline & Particle & \\
\hline & Given Name & Claire \\
\hline & Suffix & \\
\hline & Division & \\
\hline & Organization & CNRS, CEFE UMR 5175, Université de Montpellier \\
\hline & Address & Montpellier, France \\
\hline & Division & Research Centre On Biodiversity and Genetic Resources \\
\hline & Organization & CIBIO-InBio, University of Porto \\
\hline & Address & Porto, Portugal \\
\hline & Phone & \\
\hline & Fax & \\
\hline & Email & \\
\hline & URL & \\
\hline & ORCID & \\
\hline \multirow[t]{15}{*}{ Author } & Family Name & Covas \\
\hline & Particle & \\
\hline & Given Name & Rita \\
\hline & Suffix & \\
\hline & Division & Research Centre On Biodiversity and Genetic Resources \\
\hline & Organization & CIBIO-InBio, University of Porto \\
\hline & Address & Porto, Portugal \\
\hline & Division & Fitzpatrick Institute of African Ornithology, DST-NRF Centre of Excellence \\
\hline & Organization & University of Cape Town \\
\hline & Address & Cape Town, South Africa \\
\hline & Phone & \\
\hline & Fax & \\
\hline & Email & \\
\hline & URL & \\
\hline & ORCID & \\
\hline
\end{tabular}

CNRS, IPHC UMR 7178, Université de Strasbourg

Strasbourg, France

\section{Received}

24 July 2020

Schedule

Revised

Accepted

8 April 2021

Abstract

Studies on cooperative breeders have addressed the effects of non-breeding 'helpers' on reproduction and parental care, but the consequences for offspring physiology and long-term survival are less understood. Helpers are expected to benefit offspring, but their presence can also lead to decreased pre- or post-natal parental reproductive effort. To examine whether prenatal and postnatal helpers influence offspring condition, we conducted a whole-clutch cross-fostering experiment in sociable weavers (Philetairus 
socius) that altered the nestlings' social environment (presence/absence of helpers). We tested whether relative telomere length (rTL), an indicator of somatic maintenance, was influenced by prenatal and/or postnatal presence of helpers 9 and 17 days after hatching, and whether rTL predicted long-term survival. Nine days after hatching, we found an overall positive effect of postnatal helpers on rTL: for nestlings with prenatal helpers, a reduction in the number of helpers post-hatch was associated with shorter telomeres, while nestlings swapped from nests without helpers to nests with helpers had a larger rTL. However, when prenatal helpers were present, an increased number of helpers after hatching led to shorter telomeres. Nineday old chicks with longer rTL tended to be more likely to survive over the 5 years following hatching. However, close to fledging, there was no detectable effect of the experiment on rTL and no link between rTL and survival. This experimental study of a wild cooperative breeder, therefore, presents partial support for the importance of the presence of helpers for offspring rTL and the link between early-life telomere length and long-term survival.

\begin{tabular}{ll}
\hline Keywords (separated by '-') & Sociable weaver - Cross-fostering - Offspring - Early environment - Survival \\
\hline Footnote Information & $\begin{array}{l}\text { Communicated by Kevin D. Matson. } \\
\text { Supplementary Information The online version contains supplementary material available at https:// } \\
\text { doi.org/10.1007/s00442-021-04917-8. }\end{array}$
\end{tabular}




\title{
2 Contrasting associations between nestling telomere length
}

\section{and pre and postnatal helpers' presence in a cooperatively breeding} bird

\author{
Martin Quque ${ }^{1}$ (1) Matthieu Paquet ${ }^{2} \cdot$ Sandrine Zahn ${ }^{1} \cdot$ Frank Théron $^{3} \cdot$ Bruno Faivre $^{4} \cdot$ Cédric Sueur $^{1,5}$. \\ François Criscuolo ${ }^{1}$. Claire Doutrelant ${ }^{3,6} \cdot$ Rita Covas $^{6,7}$
}

Received: 24 July 2020 / Accepted: 8 April 2021

(c) The Author(s), under exclusive licence to Springer-Verlag GmbH Germany, part of Springer Nature 2021

\begin{abstract}
Studies on cooperative breeders have addressed the effects of non-breeding 'helpers' on reproduction and parental care, but the consequences for offspring physiology and long-term survival are less understood. Helpers are expected to benefit $\mathbf{A Q 1}$ offspring, but their presence can also lead to decreased pre- or post-natal parental reproductive effort. To examine whether prenatal and postnatal helpers influence offspring condition, we conducted a whole-clutch cross-fostering experiment in sociable weavers (Philetairus socius) that altered the nestlings' social environment (presence/absence of helpers). We tested whether relative telomere length (rTL), an indicator of somatic maintenance, was influenced by prenatal and/or postnatal presence of helpers 9 and 17 days after hatching, and whether rTL predicted long-term survival. Nine days after hatching, we found an overall positive effect of postnatal helpers on rTL: for nestlings with prenatal helpers, a reduction in the number of helpers post-hatch was associated with shorter telomeres, while nestlings swapped from nests without helpers to nests with helpers had a larger rTL. However, when prenatal helpers were present, an increased number of helpers after hatching led to shorter telomeres. Nine-day old chicks with longer rTL tended to be more likely to survive over the 5 years following hatching. However, close to fledging, there was no detectable effect of the experiment on rTL and no link between rTL and survival. This experimental study of a wild cooperative breeder, therefore, presents partial support for the importance of the presence of helpers for offspring rTL and the link between early-life telomere length and long-term survival.
\end{abstract}

\section{Keywords Sociable weaver $\cdot$ Cross-fostering $\cdot$ Offspring $\cdot$ Early environment $\cdot$ Survival}

Communicated by Kevin D. Matson.

Martin Quque

martin.quque@iphc.cnrs.fr

1 CNRS, IPHC UMR 7178, Université de Strasbourg, Strasbourg, France

2 Swedish University of Agricultural Sciences (SLU), Uppsala, Sweden

3 CNRS, CEFE UMR 5175, Université de Montpellier, Montpellier, France

4 Biogéosciences, CNRS UMR 6282, Université de Bourgogne Franche-Comté, Dijon, France

5 Institut Universitaire de France, Paris, France

6 Research Centre On Biodiversity and Genetic Resources, CIBIO-InBio, University of Porto, Porto, Portugal

7 Fitzpatrick Institute of African Ornithology, DST-NRF Centre of Excellence, University of Cape Town, Cape Town, South Africa

\section{Introduction}

In iteroparous species, individuals are expected to maximize their lifetime reproductive success through trade-offs between the investments in current reproduction vs. survival and future reproduction (Stearns 1977). For egg-laying species, females may vary the allocation of nutrients, antibodies, or other substances to eggs, thereby influencing the environment in which their offspring will develop. This allocation is in turn influenced by the mother's breeding environment, which is expected to be an indication of the environment in which the offspring will develop. In agreement, studies have shown that when females can anticipate the conditions experienced during reproduction they can influence traits such as egg size (e.g. Fox et al. 1997; Taborsky 2006; Vijendravarma et al. 2010), and hormonal investment (Groothuis et al. 2019), and these traits can correlate with

\begin{tabular}{|l|l|l|l|l|}
\hline Journal : Large 442 & Article No : 4917 & Pages : 14 & MS Code : 4917 & Dispatch : 12-4-2021 \\
\hline
\end{tabular}


offspring survival or behavior (e.g. Krist 2011; Paquet et al. 2015a).

Among the environmental effects experienced by females and their developing offspring, sociality has been receiving increasing attention (e.g. Russell et al. 2007, 2008; Dixit et al. 2017). In cooperatively breeding species, sexually mature non-breeding individuals_called 'helpers' - assist in raising the offspring of others by bringing additional food to the nest and performing other tasks such as territory defense (Cockburn 1998). The presence of these helpers is therefore thought to improve the breeding conditions experienced by females and/or offspring, and studies on several species have generally shown that helper presence is associated with improved juvenile condition and survival (e.g. Ridley 2007; Kingma et al. 2010; Brouwer et al. 2012; Preston et al. 2016; Tanaka et al. 2018). Breeding females may respond to this improvement in reproductive conditions by either maintaining their investment in eggs or food provisioning (Clutton-Brock et al. 2001; Doerr and Doerr 2007; Lejeune et al. 2016), or decreasing it (Crick 1992; Santos and Macedo 2011; Dixit et al. 2017), thereby reducing their cost of reproduction and increasing their survival and future reproduction. Reduction in maternal investment should then be compensated by the additional food brought by helpers (Russell and Lummaa 2009). The direction and magnitude of the response are expected to be influenced by the species' life-history strategy and especially by the effects of maternal investment on mother's survival prospects and chances of breeding successfully in the future (Russell and Lummaa 2009). In birds, cooperatively breeding species tend to be long-lived (Arnold and Owens 1998; Downing et al. 2015), and for long-lived species, maximization of lifetime reproductive success was suggested to be more efficiently achieved through increasing the number of breeding events in life than through increased investment in each breeding event (Ghalambor and Martin 2001; Drent and Daan 2002; Reid et al. 2003), In agreement, a recent meta-analysis on 10 cooperatively breeding birds highlighted a tendency for mothers to reduce egg size in larger groups in most species studied (Dixit et al. 2017; but see Fortuna et al. 2021).

It is less clear whether such differential maternal investments translate into differences in the condition and survival of offspring and what is the relative influence of the pre- and post-natal environment. For example, in birds, there are indications that larger eggs are positively associated with nestling's body size, growth and survival (Krist 2011). However, these associations could arise from genetic and hormonal effects of parents (Morrison et al. 2009; Voillemot et al. 2012; Weber et al. 2018), and/ or from rearing conditions independently from parental phenotype (Bize et al. 2002; Velando et al. 2005). From the offspring's perspective, the presence of helpers can be associated with weaker prenatal maternal egg investment
(Russell et al. 2007; Paquet et al. 2013, 2015a; Langmore et al. 2016) but identical or higher total feeding rate, as more carers are present (Sappington 1977; Wilkinson and Brown 1984; Clarke 1984; Hunter 1987). Higher levels of care can lead to increased growth rate and potentially better condition or higher body mass at fledging, and thus increased likelihood to survive the first few months after fledging (Russell et al. 2007; Canestrari et al. 2011; Loock et al. 2017). The prenatal and postnatal effects of helpers' presence can thus exert opposite influences on nestling fitness. Studies of maternal effects concerning the social environment, therefore, need to investigate the influence of these two distinct environments. This requires (i) identifying meaningful proxies of offspring fitness and (ii) conducting experiments to separate the influence of the pre- and post-natal environments.

Meaningful proxies of offspring condition should strongly correlate with offspring survival. Telomeres are repeated sequences at the ends of eukaryotic chromosomes. Replication leads to the shortening of the telomeric DNA sequence at each cell division, and beyond a certain number of cell division, telomeres become too short, triggering cell replicative senescence, which participates in the senescence of the whole organism (Tchkonia et al. 2013). Consequently, telomeres became increasingly used as predictors of agerelated survival. Telomere length (TL) and/or telomere shortening rate have been shown to predict adult survival in numerous studies involving bird species (Pauliny et al. 2006; Bize et al. 2009; Salomons et al. 2009; Heidinger et al. 2012; Barrett et al. 2013; Boonekamp et al. 2014). Both ecological (Geiger et al. 2012; Stier et al. 2014; Salmón et al. 2016; Spurgin et al. 2017) and social (Hall et al. 2004; Nettle et al. 2015; Hammers et al. 2019) environments may increase or decrease TL (see Dugdale and Richardson (2018) for a review of the environment influence on vertebrate telomere length). This influence of ecological and social environment on TL may be effective very early in an individual's life, even before birth. For example, in birds, unstable incubation temperature (Stier et al. 2020), predator cues during embryonic development (Noguera and Velando 2019), increased clutch size (Noguera and Velando 2020), or embryonic exposure to corticosterone (Haussmann et al. 2012) are all factors associated with shorter telomeres in nestlings. Although not all studies have established a clear link between telomere length and longevity or survival (e.g. Beaulieu et al. 2011; Caprioli et al. 2013; Reichert et al. 2014), the general trend in birds, mammals and reptiles is towards a consistent positive association between long telomeres and survival (Wilbourn et al. 2018). Taken together these studies support the use of telomeres as reliable indicators of longevity and/or individual quality, sensitive to early ecological and social stress, especially when measured during early life in birds (Eastwood et al. 2019). 
In this study, we conducted a cross-fostering experiment to investigate how the pre- and post-natal social environments influence offspring condition, measured by relative telomere length (rTL). In addition, we controlled for a potential trade-off suggested in the literature (e.g. reviewed in Monaghan and Ozanne 2018) between telomere length (related to self-maintenance) and mass or body condition (related to growth). We further assessed the relationship between rTL and survival by testing whether rTL predicts juvenile apparent survival as estimated with capture-markrecapture models.

Our study model was the sociable weaver (Philetairus socius), a colonial cooperatively breeding passerine endemic to the semi-arid Kalahari savannahs of southern Africa. These weavers are long-lived among passerines (up to 16 years, Covas 2012) and nest predation by snakes leads to an extremely low reproductive success (Covas et al. 2008). In sociable weavers, egg nutritional and hormonal content were negatively associated with the number of helpers at the nest (Paquet et al. 2013). On the other hand, the overall food load provided to nestlings increases when the number of helpers increases (Covas et al. 2008). In our cross-fostering experiment, we transferred whole clutches to a foster nest (see cross-fostering design in Table 1). The nestlings might thus have been conceived in the presence of helpers but raised in their absence (or vice-versa) and thus their prenatal social environment may differ from the post-natal social environment. Based on the previous knowledge of this species' life-history, and a previous result showing that females with helpers lay smaller eggs with lower levels of steroid hormones than females without helpers (Paquet et al. 2013), we predict: (i) a negative effect of the prenatal presence of helpers on chick rTL; (ii) a positive effect of the postnatal presence of helpers on chick rTL. In addition, we expect an interaction between pre- and post-natal helper presence, and we predict (iii) longer rTL of chicks that benefit from both higher maternal investment in eggs (absence of pre-hatching helpers) and additional care provided by an increased postnatal helper presence; (iv) a stronger negative impact on chick rTL when the postnatal social environment is unfavorable (decreased presence of postnatal helpers), while prenatal conditions were unfavorable too (presence of prenatal helpers). Finally, we expect that telomere length will be positively associated with survival after fledging.

\section{Material and methods}

\section{Species and study area}

The study was conducted at Benfontein Game Farm in the Northern Cape Province, South Africa (approx. $28^{\circ} 53^{\prime} \mathrm{S}$, $\left.24^{\circ} 89^{\prime} \mathrm{E}\right)$. The study area covers $15 \mathrm{~km}^{2}$ and contains approximately 30 sociable weaver colonies. The vegetation is Kalahari sandveld, consisting of open savannah dominated by Stipagrostis grasses and the camelthorn tree Acacia erioloba. The area is semi-arid, experiencing low and unpredictable rainfall (average $431 \pm 127 \mathrm{~mm} /$ year, C.V. $=35.4$; Weather Bureau, Pretoria). Most of the precipitation in the study area falls during the summer months, from September to April, when breeding usually takes place.

Sociable weavers are small (ca. $27 \mathrm{~g}$ ) sexually monomorphic passerine birds endemic to southern Namib and Kalahari regions of Southern Africa. They build a large communal nest made of numerous independent chambers, wherein the birds roost throughout the year and breeding takes place (Maclean 1973a). These weavers are facultative cooperative breeders, with up to eight helpers assisting a breeding pair in raising the chicks, notably by feeding them (Covas et al. 2008). This lighter parental workload may increase the survival of young female breeders (Paquet et al. 2015b) but has no detectable association with clutch size (Covas et al. 2008; Fortuna et al. 2021). Helpers are most often the offspring of one or both breeders (Covas et al. 2006). Younger
Table 1 Cross-fostering procedure design

\begin{tabular}{|c|c|c|}
\hline & \multicolumn{2}{|l|}{ Foster nest (postnatal) } \\
\hline & Without helpers & With helpers \\
\hline \multicolumn{3}{|c|}{ Original nest (prenatal) } \\
\hline Without helper & $\begin{array}{l}\text { Never any helper } \\
(9 \text { chicks, } 4 \text { nests }) \\
\text { EG: } 0(n=9)\end{array}$ & $\begin{array}{l}\text { Postnatal helper(s) only } \\
(11 \text { chicks, } 5 \text { nests }) \\
\text { EG: }+1(n=11)\end{array}$ \\
\hline With helpers & $\begin{array}{l}\text { Prenatal helper(s) only } \\
(12 \text { chicks, } 5 \text { nests }) \\
\text { EG: }-1(n=12)\end{array}$ & $\begin{array}{l}\text { Always at least one helper } \\
(18 \text { chicks, } 9 \text { nests }) \\
\text { EG: }+1(n=8) / 0(n=4) /-1(n=6)\end{array}$ \\
\hline
\end{tabular}

Immediately after hatching, the whole clutch was transferred from its original nest with or without helpers to a foster nest with or without helpers, resulting in chicks with a similar or different pre- and post-hatching social environment. Chicks were swapped within the same colonies. 50 chicks were involved in this procedure, the sample sizes for nestlings and nests where they come from can be read within the brackets in bold font. In bold are also indicated the corresponding experimental groups (EG; +1: increased number of helpers, 0 : no change, -1 : decreased number of helpers) 
helpers are both males and females while, when older than one year, helpers are usually males (Doutrelant et al. 2004). There is no extra-pair paternity in this species (Covas et al. 2006; Paquet et al. 2015b). Sociable weavers feed mostly on insects, but also seeds and other plant products (Maclean 1973b).

\section{Data collection}

Data were collected between September 2013 and February 2014 (for the variables related to breeding, growth, and telomeres) and until 2019 for chick survival. Unique numbered aluminum ring and color combination are attributed to each adult during the annual captures in winter and to each nestling before fledging, allowing individual identification of each bird. During the breeding season, all chambers in the study colonies are checked every three days, allowing us to identify new clutches and estimate clutch size (in this study, clutch size: mean $=3.5$ and $\mathrm{SD}=0.57 \mathrm{eggs} ;$ brood size before fledging: mean $=2.25$ and $\mathrm{SD}=0.84$ birds). All chambers are visited daily at the end of the incubation period (approximately 15 days), to identify the hatching date. The nestling period usually lasts 21-24 days (Maclean 1973a). Two sets of measurements were performed nine days (D9) and seventeen days (D17) after the first chick hatched in each nest. Hence, chicks were captured only twice, limiting stress. D9 is the earliest moment where all chicks can be ringed and sampled for blood and D17 was chosen to have a measure as late as possible before fledging (as nestlings will fledge prematurely if handled from day 18 onwards). At these two dates, we measured brood size (number of chicks) and nestling mass, and we took blood samples from the brachial vein for sex determination and telomere analysis. This procedure was conducted on a total of 132 nestlings distributed among 15 colonies (containing approximately 400 chambers). In our study, we observed that approximately $39 \%$ of the individual nests (chambers) lacked helpers, whereas $61 \%$ had helpers. Individual nests harbored from 0 to 4 helpers and the average group size (parents + potential helpers) was 3.2 birds (median $=3, \mathrm{SD}=1.2$ ).

Blood samples at D9 were stored in 95\% ethanol. In contrast, because of use in other experiments, blood samples at D17 were centrifuged immediately upon collection and red blood cells were stored frozen. Because different storage conditions may affect rTL measured via quantitative polymerase chain reaction (qPCR, Reichert et al. 2017), we restricted our analysis to the same nestling age comparisons, storage conditions within samples from the same nestling age being strictly identical and could not affect the outcomes.

Tarsus length at D17 was also recorded and used as a proxy for body size. The body condition of a chick was calculated as the residual value from the regression between tarsus length and mass at D17 (regression plot and statistics available in Electronic Supplementary Material, ESM 1). Tarsus length was not measured at D9. The 15 colonies from where the 132 chicks in this study originated are monitored annually, allowing us to analyze the relationship between the early rTL and survival from birth to the present (6 years).

\section{Cross-fostering procedure}

The detailed methods can be found in Paquet et al. (2015a), with the difference that here we focused on the reproduction period from September 2013 to February 2014. In brief, when two clutches from the same colony and of the same size were laid synchronously (or within a 1-day interval), both whole clutches were swapped on the day after the last egg was laid. Group sizes after hatching (i.e. parents + number of postnatal helpers) were established by counting the number of birds seen feeding the chicks. Observations and counting took place from under a hide placed at 3-5 $\mathrm{m}$ from the colony. The group size within a nest usually remains stable during the breeding cycle (from nest building to offspring fledging; Paquet et al. 2016), allowing us to infer the number of helpers before cross-fostering retrospectively. Within the 132 nestlings sampled during this study, 72 were involved in the cross-fostering protocol, among them, the presence (or absence) of helpers was known for 50 of them (18 broods). The pre- and post-natal social environments for these 50 chicks are detailed in Table 1.

\section{Telomere length measurements}

To assess the prenatal and postnatal effect of helpers on chick rTL, we measured early relative telomere length at D9 and just before fledging at D17 in chicks using the qPCR procedure. This protocol was first developed by Cawthon (Cawthon 2002) and thereafter popularized in birds' studies (Criscuolo et al. 2009; Herborn et al. 2014; Nettle et al. 2015; Meillère et al. 2015; Costanzo et al. 2017). The qPCR provides a non-absolute measure of an individual's TL, a relative telomere length as it is expressed relatively to one specific sample that is given arbitrarily the value of 1 (see Nussey et al. 2014; Lai et al. 2018) for a comparison between TL measurement methods). Shortly, after genomic DNA extraction from red blood cells (nucleated in birds) using silicamembrane columns (Nucleospin Blood QuickPure, Macherey-Nagel, Düren, Germany), DNA quantity and quality were assessed based on spectrophotometer absorbance (Nanodrop 1000 Thermo Scientific, ratios A260/280 and A260/230) and gel-migration (on a sub-sample randomly chosen of 30 samples, see ESM 2). Dilutions of extracted DNA (at $2.5 \mathrm{ng} / \mathrm{uL}$ ) were prepared using sterile distilled water and were amplified using telomere and control gene primers with the BRYT Green fluorescent dye (GoTaq qPCR 
Master Mix, Promega Charbonnières-les-Bains, France). We used recombination activating gene RAG1 as our control gene for weavers, designed to be non-variable among the individuals of our population (as advised by Smith et al. 2011; see ESM 2). The forward and reverse primers for the control gene were: SOWEA-F: 5'-TGCAAAGAGATTTCG ATATGATG-3', SOWEA-R: 5'-TCACTGACATCTCCC ATTCC-3'. Tellb: 5'-CGGTTTGTTTGGGTTTGGGTT TGGGTTTGGGTTTGGGTT-3', Tel2b: 5'-GGCTTGCCT TACCCTTACCCTTACCCTTACCCTTACCCT-3' for the telomere amplification. An automated thermocycler (CFX 384 Biorad Hercules, USA) was used, with reaction conditions set at $95{ }^{\circ} \mathrm{C}$ for $2 \mathrm{~min}$, followed by 40 cycles of data collection at $95{ }^{\circ} \mathrm{C}$ for $1 \mathrm{~min}$ and a $60^{\circ} \mathrm{C}$ annealing-extension step for $1 \mathrm{~min}$ for RAG1. For the telomeric sequence, the conditions were set at $95{ }^{\circ} \mathrm{C}$ for 2 min followed by 30 cycles of data collection for $15 \mathrm{~s}$ at $95^{\circ} \mathrm{C}, 30 \mathrm{~s}$ at $56^{\circ} \mathrm{C}$, and $1 \mathrm{~min}$ at $72{ }^{\circ} \mathrm{C}$. The 132 weaver samples used in the present study were part of 504 samples that were measured in duplicates on 5 different runs. Each run includes 1 plate of telomere sequence amplification and 1 plate of control gene sequence amplification, due to the differences in qPCR temperature conditions. On each plate, we ran a dilution curve (20-0.313 ng) to check that the efficiency of amplification did not vary among plates, and a melting curve to check for amplification artifacts (like primer-dimer signal, see ESM 2). The mean qPCR amplifying efficiencies were $99.8 \%$ (99.4-99.9) for telomere and 99.9\% (99.7-100.1) for the control gene (100\% reflect a doubling of the DNA sequence at each amplification step). Samples were randomly distributed over the plates, and 40 were repeated to assess interplate variation. As advised by Eisenberg (2016), rather than coefficients of variation, we reported the interplate and intraplate intra-class correlation coefficients for $\mathrm{T} / \mathrm{S}$ ratio, respectively, 0.895 and 0.767 .

The rTL is then calculated from the T/S ratio, where ' $\mathrm{T}$ ' is the copy number of the telomeric sequence and ' $\mathrm{S}$ ' is the copy number of the control sequence. We took into account the slight variation of efficiency between telomere and RAG1 amplifications by calculating the T/S ratio accordingly to Pfaffl's recommendation (Pfaffl 2001):

$\left[\left(1+\mathrm{E}_{\text {(telomere) }}\right)^{\wedge} \Delta \mathrm{Cq}_{\text {(telomere) }}\right] /\left[\left(1+\mathrm{E}_{(\mathrm{RAG} 1)}\right)^{\wedge} \Delta \mathrm{Cq}_{(\mathrm{RAGl})}\right]$ where ' $\mathrm{E}$ ' is the amplification efficiency and ' $\Delta \mathrm{Cq}$ ' the difference in time required to reach the fluorescence detectability threshold between control and sample (Cqcontrol-Cqsample).

\section{Statistical analysis}

Categorical variables were tested through ANOVA (package 'stats' v.3.6, R Core Team 2019). Post-hoc comparisons were done using the multcomp $\mathrm{R}$ package with Tukey contrasts corrections (Hothorn et al. 2008). Quantitative variables including the $\mathrm{T} / \mathrm{S}$ ratio were first $\mathrm{z}$-scored and then tested directly through the $\mathrm{t}$ statistics provided by default by the function 'Imer'. Statistical tests were performed by the R software (R Core Team 2019) at the significance threshold $\alpha=5 \%$.

\section{Effects of helpers on chick telomere length: definition of variables}

In our analysis, we considered the effects of (i) the natural presence of helper in the nest of origin (hereafter referred to as 'prenatal presence') and (ii) the postnatal change in helper presence induced by the cross-fostering (hereafter referred to as 'postnatal helper change'). The prenatal presence of helpers was coded 0 (no helpers) and 1 (presence of helpers) while the postnatal helper change was coded 0 (no change), -1 (reduced number of helpers) and +1 (presence or increased number of helpers).

We tested if the prenatal presence of helpers and the postnatal helper change, as well as their interaction had an impact on early telomere length (i) nine days after hatching and (ii) later, just before fledging, at seventeen days after hatching. Telomere length and dynamics are known to be affected by individual characteristics, such as sex (Barrett and Richardson 2011; Young et al. 2013) or growth rate (Ringsby et al. 2015; Monaghan and Ozanne 2018; Vedder et al. 2018), as well as by the social environment (Hall et al. 2004; Nettle et al. 2015; Dugdale and Richardson 2018; Hammers et al. 2019). Hence, in addition to the prenatal presence and the postnatal helper change, we tested the influence of the following explanatory variables: sex, breeding period (different climatic conditions), brood size (intra-nest social competition), and body condition (an indicator of chick growth). The breeding period had two levels: the first between October and November 2013 (sparse rains) and the second between December 2013 and January 2014 (abundant rains). The prenatal presence of helpers and the postnatal helper change were not correlated: $\chi^{2}=0.040$, $P=0.842$ ), which validates the randomness of the crossfostering procedure. Moreover, there was no evidence for collinearity between all other variables (Variance Inflation Factors were less than three: $\mathrm{VIF}_{\max }=1.49$ ).

\section{Effects of helpers on chick telomere length: model fitting and selection}

For the tests conducted either on day 9 or day 17, we built separated mixed linear models (LMM) with 'nest' as a random factor nested in 'colony' to control for non-independence of chicks in a nest. Due to the relatively low sample size $(n=50)$, we decided not to include more than five 
explanatory variables to avoid over fitting (Harrison et al. 2018). We applied a model selection procedure with the 'MuMIn package on R, based on the lowest Aikake's information criterion corrected for small sample sizes (AIC; $\mathrm{v}$. 1.43 Barton 2013). The procedure was adjusted to provide models containing no more than five variables, including the two main effects we wanted to test, i.e., prenatal presence and postnatal variation in the number of helpers. We chose models as complete as possible with a maximum $\triangle \mathrm{AIC}$ of 2 . Then, depending on the selection procedure, the interaction term 'prenatal presence $\mathrm{x}$ postnatal helper change' may not be included in the lowest AIC model. All proposed and selected models involving telomere length are available in the electronic supplementary material (ESM 3, Table S1). We graphically ensured that model residuals did not significantly differ from a Gaussian distribution and related Anderson-Darling's tests had $P$ value $>0.05$ for rTL both 9 and 17 days after hatching, respectively, $\mathrm{A}=0.25, P=0.72$ and $\mathrm{A}=0.33, P=0.51$, indicating that the model residuals fitted a normal distribution.

A Pearsons' correlation test was conducted to test for correlation of intra-individual values of chick telomere lengths repeatedly measured at day 9 and day 17 post-hatch.

\section{Chick body condition and body mass growth vs. telomere length}

Chick body condition was calculated as the residuals of the regression of body mass vs. tarsus length both measured at D17. Using the same statistical procedure as for telomere length, we tested whether the effect of helpers could be reflected in the body condition of chicks through mixed linear models with mass at D9 and body condition at D17 as dependent variables. Full models used in the model selection procedure included brood sizes at D9 or D17, chick sex and season, as well as nest/colony as random factors. Furthermore, we used the same statistical approach to examine the link between body condition at D17, body mass at D17 or body mass gain between D9 and D17 and chick telomere length at D17.

\section{Telomere length and apparent survival}

To estimate whether rTL predicted apparent survival we fitted Cormack-Joly-Seber (CJS) models (Gimenez et al. 2007) on six years of capture-mark-recapture history of 132 fledglings (59 females and 73 males from cross-fostered as well as non-cross-fostered nests). We measured apparent survival, which does not allow us to differentiate dead individuals from those that permanently dispersed beyond the area studied. However, both sexes are philopatric (Dijk et al. 2015), and the 15-20 colonies in the study area are captured yearly, allowing us to re-capture birds dispersing between colonies (usually less than 10\%; Covas 2011). Furthermore, $\mathbf{A Q 3}_{5}$ by considering detectability values lower than one, CMR 466 models offer a reliable and explicit way to perform survival $\quad 467$ analysis in the wild (Gimenez et al. 2008). The CJS model 468 is composed of apparent survival probability $\boldsymbol{\phi}$ (defined as 469 the probability to survive and not permanently emigrate $\quad 470$ the next year) and recapture probability $\boldsymbol{p}$ (defined as the 471 probability of an individual apparently alive in a year to be 472 recaptured with mist nets that year). We set $\phi$ to vary lin- 473 early with rTL (scaled) on the logit scale. We also allowed 474 both $\boldsymbol{\phi}$ and $\boldsymbol{p}$ to vary with the sex of the individuals as we 475 expected them to be lower for females (Dijk et al. 2015; 476 Paquet et al. 2015b) and to make sure that any relationship 477 between rTL and apparent survival was not solely due to sex 478 differences. We found an average recapture probability of 479 $0.722(\min =0.568, \max =0.854)$ for females and of 0.826480 for males $(\min =0.738, \max =0.900)$.

We specified both capture-recapture models using JAGS, version 4.2.0 (Plummer 2015) run using the rjags package (Plummer 2013) in Program R, version 3.4.3 (see ESM 4 for JAGS code). We estimated parameters using vague priors (see ESM 4 for priors and initial values). We used 3000 posterior samples from three Markov Chain Monte Carlo (MCMC) chains based on 3000 iterations after an adaptation period of 5000, a burn-in of 10,000 and thinning interval of 3 . We assessed model convergence both visually and by using the "R hat" Gelman-Rubin statistic (Gelman and Rubin 1992) and found the $95 \%$ upper limits of potential scale reduction factors to equal 1 for all estimated parameters, indicating that convergence was achieved. We assessed the fit of our two models to the data (i.e. posterior predictive checks) by simulating capture recaptures histories from our two models at each iteration and comparing the number of simulated recaptures for the 3000 posterior samples with the number of observed recaptures. Simulated values systematically lower or higher than observed values would indicate a lack of fit [i.e. $p$ (simulated < observed) close to 0 or 1]. We obtained $p$ (simulated $<$ observed $)=0.47$ and 0.49 for models looking at rTL at D9 and D17, respectively, indicating a good fit to the data.

\section{Ethical statement}

All experiments were conducted with permission from the Northern Cape Department of Tourism Environment and Conservation (permit FAUNA 942/2012) and the approval of the Ethics Committee of the University of Cape Town (2009/V12/RCREN). Our procedures involved the capture, confinement, handling, and blood sampling of the birds in the field, with the time elapsed between extracting the birds from the nets until the last bird was released ranging from 2 to $3 \mathrm{~h}$. While queuing to be processed, birds rested in individual bird bags and were placed in a 
quiet, ventilated and shaded area. The sampling volume (ca. $75 \mu \mathrm{l}$ ) remained well below the prescribed limits for the percentage of the total blood volume of this passerine. After handling, the adult birds could recover for a few minutes before being released in small groups. Any birds that showed signs of fatigue or injury were taken to an indoor aviary to recover and were subsequently released. This happened for less than $1 \%$ of the birds handled. To decrease handling times, captures were conducted with a team of 8-12 experienced ringers that were allocated specific tasks to streamline the procedures conducted.

\section{Results}

We present for each result below the estimate \pm standard error in brackets. In Table 2 (telomere-related models) and Table 3 (body mass-related models), we present in addition $95 \%$ confidence interval (CI95\%), test statistics and $P$ values. After the model selection procedure (detailed in ESM 3, Table S1), all models contained the following independent variables: prenatal presence, postnatal helper change and the random effect of the nest nested in the colony. The interaction between pre- and post-natal helpers (prenatal presence $\times$ postnatal helper
Table 2 Effect of the prenatal and postnatal presence of helpers on chick relative telomere length (rTL,

\begin{tabular}{|c|c|c|c|c|c|}
\hline \multirow[t]{2}{*}{ Predictors } & \multicolumn{5}{|l|}{ rTL D9 } \\
\hline & Estimates & Std. error & $\mathrm{CI}$ & Statistic & $P$ \\
\hline \multicolumn{6}{|l|}{ (a) } \\
\hline Intercept & -0.08 & 0.55 & $-1.17-1.00$ & -0.15 & 0.880 \\
\hline Prenatal presence of helpers & 0.29 & 0.45 & $-0.58-1.17$ & 0.65 & 0.513 \\
\hline Postnatal helper change & 1.18 & 0.50 & $0.20-2.16$ & 2.36 & 0.018 \\
\hline Brood size D9 & 0.09 & 0.17 & $-0.24-0.43$ & 0.54 & 0.587 \\
\hline Chick sex & -0.43 & 0.25 & $-0.91-0.05$ & -1.74 & 0.082 \\
\hline $\begin{array}{l}\text { Prenatal presence } \times \text { postnatal } \\
\text { helper change }\end{array}$ & -1.7 & 0.54 & -2.81 to -0.70 & -3.27 & 0.001 \\
\hline \multicolumn{6}{|l|}{ Random effects } \\
\hline$\sigma^{2}$ & 0.46 & & & & \\
\hline$\tau_{00}($ nest:colony_id $)$ & 0.50 & & & & \\
\hline$\tau_{00}($ colony_id $)$ & 0.39 & & & & \\
\hline ICC & 0.66 & & & & \\
\hline $\mathrm{N}$ (nest) & 18 & & & & \\
\hline N (colony_id) & 3 & & & & \\
\hline Observations & 50 & & & & \\
\hline Marginal $R^{2} /$ conditional $R^{2}$ & $0.177 / 0.718$ & & & & \\
\hline Intercept & 1.91 & 0.17 & $1.57-2.25$ & 11.04 & $<0.001$ \\
\hline Prenatal presence of helpers & -0.13 & 0.21 & $-0.53-0.28$ & -0.61 & 0.542 \\
\hline Postnatal helper change & -0.06 & 0.12 & $-0.29-0.18$ & -0.48 & 0.635 \\
\hline Breeding season & 0.12 & 0.18 & $-0.23-0.46$ & 0.66 & 0.508 \\
\hline \multicolumn{6}{|l|}{ Random Effects } \\
\hline$\sigma^{2}$ & 0.39 & & & & \\
\hline$\tau 00$ (nest:colony_id) & 0.00 & & & & \\
\hline$\tau 00$ (colony_id) & 0.00 & & & & \\
\hline $\mathrm{N}$ nest & 18 & & & & \\
\hline N (colony_id) & 3 & & & & \\
\hline Observations & 50 & & & & \\
\hline Marginal $\mathrm{R}^{2} /$ conditional $\mathrm{R}^{2}$ & $0.017 / \mathrm{NA}$ & & & & \\
\hline
\end{tabular}

The following tables list the estimates ('est.'), 95\% confidence interval ('CI 95\%'), standard error ('SE'), test statistics ('stat.', $t$ or $F$, respectively, for continuous or categorical variables) and $P$ values (' $P$ ') from linear mixed models. We only consider the variables retained after the model selection procedure (ESM 3). Continuous variables have been scaled and transformed into z-scores. Lines in bold indicate a significant test with $\alpha=0.05$ as a threshold. Results are given for chick telomere length at 9 (a) and 17 (b) days after hatching. In this latter case, random effects did not explain a significant part of the variance

\begin{tabular}{|l|l|l|l|l|}
\hline Journal : Large 442 & Article No : 4917 & Pages : 14 & MS Code : 4917 & Dispatch : 12-4-2021 \\
\hline
\end{tabular}


Table 3 Effect of the prenatal and postnatal presence of helpers on the chick mass at day 9 (a) and chick body condition at day 17 (b) post-hatch (linear mixed models)

\begin{tabular}{|c|c|c|c|c|c|}
\hline \multirow[t]{2}{*}{ Predictors } & \multicolumn{5}{|c|}{ Body mass D9 (g) } \\
\hline & Estimates & Std. error & CI & Statistic & $P$ \\
\hline \multicolumn{6}{|l|}{ (a) } \\
\hline Intercept & 2.01 & 0.99 & $0.06-3.96$ & 2.02 & 0.044 \\
\hline Prenatal presence of helpers & 0.51 & 0.43 & $-0.32-1.35$ & 1.20 & 0.231 \\
\hline Postnatal helper change & 0.14 & 0.59 & $-1.00-1.29$ & 0.24 & 0.808 \\
\hline Brood size D9 & -0.88 & 0.23 & -1.34 to -0.42 & -3.77 & $<0.001$ \\
\hline Chick sex & 0.51 & 0.26 & $-0.01-1.02$ & 1.94 & 0.053 \\
\hline $\begin{array}{l}\text { Prenatal presence } \times \text { postnatal } \\
\text { helper change }\end{array}$ & 0.35 & 1.09 & $-1.79-2.49$ & 0.32 & 0.752 \\
\hline \multicolumn{6}{|l|}{ Random Effects } \\
\hline$\sigma^{2}$ & 0.62 & & & & \\
\hline$\tau 00$ (nest:colony_id) & 0.11 & & & & \\
\hline$\tau 00$ (colony_id) & 0.46 & & & & \\
\hline ICC & 0.48 & & & & \\
\hline $\mathrm{N}$ (nest) & 18 & & & & \\
\hline N (colony_id) & 3 & & & & \\
\hline Observations & 50 & & & & \\
\hline Marginal $R^{2} /$ conditional $R^{2}$ & $0.255 / 0.611$ & & & & \\
\hline \multicolumn{6}{|l|}{ (b) } \\
\hline Intercept & -0.99 & 0.50 & $-1.97-0.00$ & -1.95 & 0.051 \\
\hline Prenatal presence of helpers & 0.36 & 0.40 & $-0.42-1.15$ & 0.90 & 0.367 \\
\hline Postnatal helper change & 0.90 & 0.44 & $0.04-1.77$ & 2.04 & 0.041 \\
\hline Breeding season & 0.55 & 0.28 & $-0.00-1.11$ & 1.95 & 0.051 \\
\hline Chick sex & 0.16 & 0.21 & $-0.26-0.58$ & 0.76 & 0.450 \\
\hline Brood size D17 & -0.51 & 0.15 & -0.80 to -0.21 & -3.37 & 0.001 \\
\hline \multicolumn{6}{|l|}{ Random effects } \\
\hline$\sigma^{2}$ & 0.34 & & & & \\
\hline$\tau 00$ (nest:colony_id) & 0.59 & & & & \\
\hline$\tau 00$ (colony_id) & 0.00 & & & & \\
\hline ICC & 0.63 & & & & \\
\hline $\mathrm{N}$ (nest) & 18 & & & & \\
\hline $\mathrm{N}$ (colony_id) & 3 & & & & \\
\hline Observations & 50 & & & & \\
\hline Marginal $R^{2} /$ conditional $R^{2}$ & $0.257 / 0.728$ & & & & \\
\hline
\end{tabular}

None shows a significant effect of helpers. Testing body mass at D17 or body mass gain between D9 and D17 led to similar non-significant effects (data not shown) change), as well as chick sex and brood size were kept only for the presence of helpers at D9. Only the breeding season was kept as an additional fixed factor for the model testing individual variability in rTL at D17. The original data sets regarding both the effect of helpers on chick rTL and the effect of rTL on survival are available online as distinct tables in ESM5. Chicks rTL measured at D9 and D17 were found to be significantly correlated-even if the correlation is not high $(r=0.27, t=2.64, P=0.009$, $n=93$, Pearson's correlation).

\section{Effect of the prenatal and postnatal presence of helpers on chick rTL}

The detailed statistics are given in Table 2 and related plots are Fig. 1a for D9 and 1B for D17.

Nine days after hatching, we found a significant interaction between the prenatal helpers' presence and the postnatal helpers' presence $(-1.76 \pm 0.54)$. The Tukey contrasts post-hoc comparisons showed that for the chicks from nests without helpers during the prenatal stage, obtaining

\begin{tabular}{|l|l|l|l|l|}
\hline Journal : Large 442 & Article No : 4917 & Pages : 14 & MS Code : 4917 & Dispatch : 12-4-2021 \\
\hline
\end{tabular}




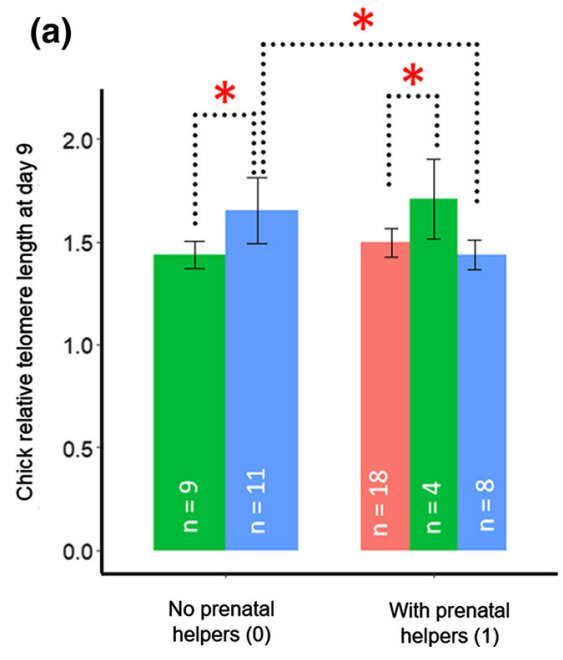

Fig. 1 Relative telomere length (rTL, T/S ratio) 9 days (a) and 17 days (b) after hatching in relation to helpers' presence in sociable weavers. We compared the rTL of 50 cross-fostered individuals according to (i) the presence of helpers before the cross-fostering and (ii) after the cross-fostering. This latter experimental factor is categorised as increased number of helpers $(+1$, blue); no change in helpers' presence $(0$, green) and decreased number of helpers $(-1$, red). a Post-hoc significant differences (Tukey contrasts) concerned: longer

postnatal helpers was associated with larger rTL nine days after hatching (Fig. 1a, 0/1 vs 0/0, post-hoc: $1.54 \pm 0.49$, $z=3.13, P=0.01)$. For chicks that had prenatal helpers, a decrease in the number of helpers was associated with a shorter rTL $(1 /-1$ vs $1 / 0$, post-hoc: $-1.21 \pm 0.44, z=-2.75$, $P=0.042$ ). However, the rTL of chicks swapped from nests with helpers to nests with more helpers was not affected by the increase in helper number after hatching $(1 /+1$ vs $1 / 0$ and $1 /-1$, post-hoc: respectively, $-1.23 \pm 1.20, z=-1.03$, $P=0.83$ and $1.20 \pm 0.51, z=2.35, P=0.12$ ). Among the chicks experiencing additional helpers, those with prenatal helpers had shorter telomeres on average $(0 /+1$ vs $1 /+1$, post-hoc: $-1.18 \pm 0.44, z=-2.73, P=0.043)$. The effect of chick sex and brood size were not significant (respectively, $-0.43 \pm 0.25$ and $0.09 \pm 0.17$ ). When measured at D17 post-hatch, neither the prenatal presence or the postnatal helper change nor their interaction term were found to be significantly related to offspring's rTL (Fig. 1b, Table 2b). The breeding season, while kept in the selected model, had no significant effect $(0.12 \pm 0.18)$.

\section{Effects of helpers on chick body mass and body condition}

Neither the prenatal or the postnatal presence of helpers were associated with a change in chick body mass at D9, or chick body condition at D17 (Table 3). Only brood sizes (D9 and D17) negatively affected body mass at D9 and body condition at D17, respectively. Testing body mass at D17 or

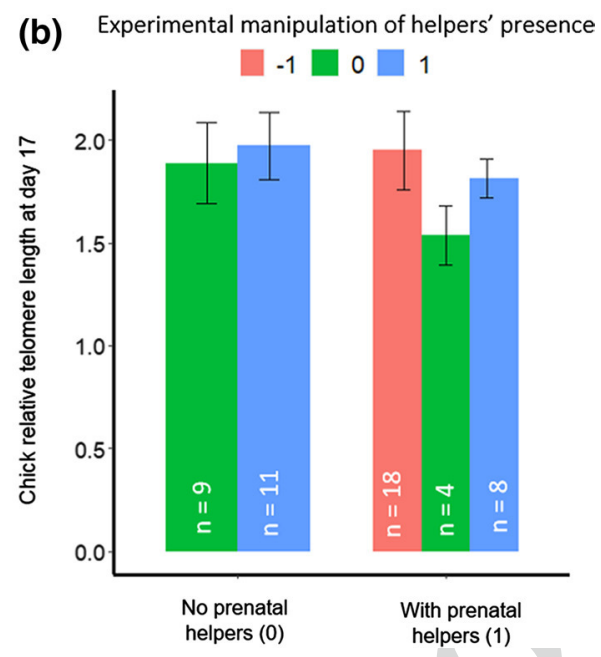

rTL in chicks that started with no helpers but get experimental helpers' presence $(P=0.010)$; decreased rTL in chicks that started with helper presence but thereafter experienced no helpers $(P=0.042)$; shorter rTL in chicks that started with helpers and experienced increased helpers presence after hatching compared to chicks that had helpers only after hatching $(P=0.043)$. b no significant differences were found at D17. See text for statistics. Error bars represent standard errors. White numbers inside the bars give the sample size

the gain in body mass between D9 and D17 did not shown any significant relationships (data not shown). There was no relationship between body mass gain (D17-D9) and chick rTL at D17 (ESM 6, Table S2).

\section{Chick telomere length and apparent survival rate}

We found that sociable weaver chicks with longer rTL at D9 tended to have a higher apparent survival rate the following five years although the $95 \%$ credible interval overlapped zero [estimate $(95 \%$ credible interval $)=0.21(-0.072,0.52)$,

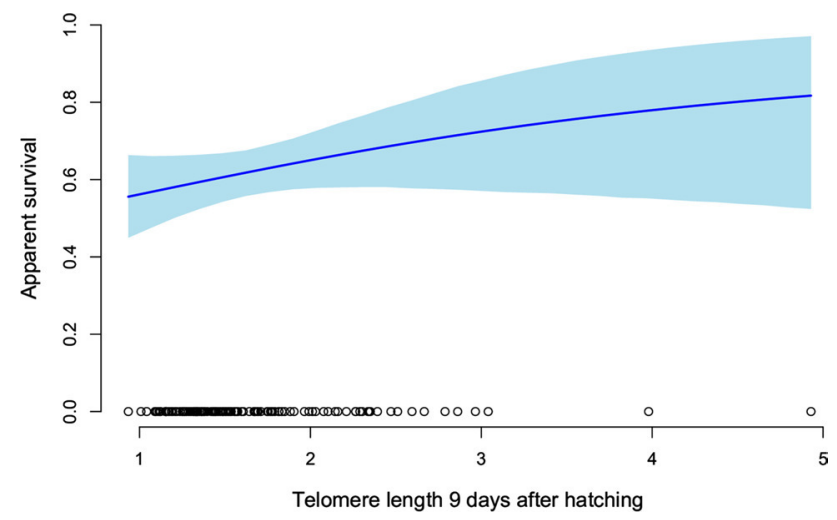

Fig. 2 Relation between relative telomere length (rTL, T/S ratio) 9 days after hatching and apparent survival. 132 birds were annually captured from 2014 to the present (6 years). Estimate and 95\% Credibility Interval $=0.21(-0.07 ; 0.52), p($ estimate $>0)=0.928$

\begin{tabular}{|l|l|l|l|l|}
\hline Journal : Large 442 & Article No : 4917 & Pages : 14 & MS Code : 4917 & Dispatch : 12-4-2021 \\
\hline
\end{tabular}


$p$ (estimate $>0)=0.928$, Fig. 2]. We found no clear association between rTL at D17 and apparent survival [estimate $=-0.013(-0.24,0.22), p($ estimate $>0)=0.458]$.

\section{Discussion}

We investigated the influence of the prenatal and postnatal presence of helpers on rTL and the link between rTL and survival in nestlings of the sociable weaver, a cooperatively breeding bird. Early-life rTL (i.e. measured nine days after hatching) was overall positively associated with the presence of post-natal helpers but was also influenced by an interaction of the presence of pre- and post-natal helpers. Specifically, we found that for chicks coming from nests without prenatal helpers, rTL was longer when postnatal helpers were added after hatching. For the chicks coming from nests that already had prenatal helpers, telomere length was shorter when the number of helpers decreased after hatching. For those chicks, however, an increase in the number of postnatal helpers had no significant effect on offspring rTL. The interaction between the prenatal presence and postnatal helper change showed that the increase in postnatal helpers was associated with a greater offspring rTL only when no prenatal helper was present. The effects observed nine days after hatching (D9) were not observed at the end of the nestling period (D17; but see below). Finally, the CMR analysis conducted to assess the link between early rTL and post-fledgling survival showed a tendency for rTL at D9 to be positively related to survival up to five years after hatching, but this relationship was no longer present at D17.

\section{Contrasting effects of pre- and post-natal helpers on offspring's telomeres}

Nestlings from original nests without helpers had greater rTL at D9 when raised with postnatal helpers than without. On the other hand, reducing the number of postnatal helpers (i.e. concerned nests with prenatal helpers) was associated with shorter chicks' rTL. These two findings support a beneficial effect of post-hatching helpers on offspring rTL in sociable weaver. Such positive postnatal influence is thought to be mediated by the enhancement of developmental conditions that nestlings experience through the additional care provided (Covas et al. 2008; Bebbington et al. 2018). This additional care may also contribute to decreasing sibling competition in larger broods, which has been shown as a modulating mechanism of rTL in chicks from different species (Voillemot et al. 2012; Boonekamp et al. 2014; Nettle et al. 2015; Young et al. 2017). A negative effect of sibling competition on offspring development was also suggested here through a negative effect of brood size on body mass. Nevertheless, this beneficial effect appears to be limited, since the addition of postnatal helpers in nests already harboring prenatal helpers had no significant effect.

We found in addition an interaction between the prenatal presence and postnatal helper change indicating that the positive effect of postnatal helpers on chick rTL is dependent on the presence of prenatal helpers. Indeed, adding helpers after hatching was negatively associated with chick's rTL if those chicks had experienced prenatal helpers (i.e. they had on average shorter rTL than those without prenatal helpers); the effect persisted even when removing the two extreme values for the $0 / 1$ condition (Fig. 1a). This outcome is expected if there is a prevalent negative prenatal effect resulting from a reduced maternal investment during egg production in presence of prenatal helpers, compared to the benefits of being raised with post-natal helpers. In fact, previous studies have shown that the conditions experienced during embryonic life may alter telomere length at birth (Entringer et al. 2011; Haussmann et al. 2012; Vedder et al. 2018; Noguera and Velando 2019, 2020; Stier et al. 2020). Sociable weavers females were found to lay smaller eggs with lower steroid hormone content (Paquet et al. 2013). Telomere shortening may thus arise from this weaker maternal investment in the presence of pre-hatching helpers. Our results suggest that such initial telomere handicap may not be reversed by the beneficial effects of post-natal helpers. Still, our sample size does not allow us to draw definitive conclusions, and the pre/ post-natal helpers interaction effects deserve further study.

A non-exclusive explanation for the lack of a positive effect of an increased number of postnatal helpers for nestlings with prenatal helpers might be that, above an optimal threshold, adding more helpers would have no benefits, or could even become detrimental for offspring rTL. A previous study in the same species has actually shown that larger group sizes may result in a weaker offspring survival likelihood (Covas et al. 2011, but see Wood 2017 chap. 3). When analyzing only the effect of group size before and after hatching, we found that the number of helpers had no effect on telomere length at either D9 or D17 (ESM 7). This confirms the results presented here and supports the interpretation that, in our case, a larger number of helpers does not provide greater benefits for the offspring, whatever their age. In addition, a previous study on this population found that the positive effect of helpers on chicks after hatching is mostly detected under adverse environmental conditions (Covas et al. 2008). If fewer helpers provide sufficient help under usual climatic conditions, this may explain why we found no significant effect of an increased number of helpers post-hatch when prenatal helpers were already present $(1 /+1$ vs $1 / 0$ and $1 /-1)$. Given the association between helpers' presence and rTL at day 9, it may be surprising to find no association at day 17. However, in addition to the presence of helpers, several environmental factors such as climate (Mizutani et al. 2013), sibling rivalry (Nettle et al. 
2015; Mizutani et al. 2016) or food availability (Spurgin et al. 2017) might have blurred possible helper effects at D17. For example, in black-tailed gull chicks (Larus crassirostris), the effect of sibling competition on telomeres was weak on the first day after hatching and became stronger 30 days after hatching, potentially concealing the effect of other factors (Mizutani et al. 2016). In European starlings (Sturnus vulgaris), the effect of sibling rivalry on telomere attrition was also dependent on nestling age: not detectable at 3 days after hatching (D3), detectable at D12 and faded at D24 (Nettle et al. 2015). In the same study, the effect on oxidative status was detectable at D3 but no longer at D12. Those studies and ours seem to indicate that the effect of different environmental factors might vary with individual age and species.

\section{Body mass growth, telomeres, and survival}

The suggestion that offspring's early rTL is a proxy of survival rate has been supported in other species (Geiger et al. 2012; Heidinger et al. 2012; Stier et al. 2014; Young et al. 2017; Eastwood et al. 2019; Chatelain et al. 2020); but see (Boonekamp et al. 2014) or (Wood and Young 2019) for a critical view on telomere shortening and survival. Although the $95 \%$ credible interval slightly overlapped zero, our study tends also to suggests that chick rTL early after hatching might predict post-fledging apparent survival, at least up to 5 years after hatching. In this species, a previous study showed that helpers had a negative effect on offspring survival but only during the first year after fledging, after that, this negative effect disappeared (Covas et al. 2011). Even if in the medium term (five years here) the presence of postnatal helpers seems to be rather positive for offspring apparent survival, the consequences of helpers could be more complex especially in the very first years of life. This adds another level of complexity in understanding the evolutionary advantages and disadvantages of social structure involving cooperative breeding.

Heidinger et al. (2012) have shown that rTL measured within the first month in zebra finches predicted lifespan better than subsequent measurements. Our results are in line with this finding, as we did not detect an association between rTL and apparent survival for older chicks (before fledging). However, the exact reasons for why earlier telomere length is a better predictor or survival than later telomere length remain elusive (Ingles and Deakin 2016; Lieshout et al. 2019).

The improved rearing conditions induced by postnatal helpers could have led also to improve body condition. However, and similarly to a previous study in the same species (Paquet et al. 2013), both mass at D9 and fledglings' body condition (D17) did not vary with the presence of helpers. These results support previous suggestions on this and other species in showing the ability of helpers to compensate for the differential maternal investment in eggs so that, on average, fledglings have the same body condition. Since, in our study, chicks varied in their day 9 rTL but not body condition, it seems that for the chicks that do not have helpers, allocation of energy is toward growth at the expense of their telomeres. Such a trade-off between growth and telomere maintenance has been shown in numerous vertebrate species (Tarry-Adkins et al. 2009; Geiger et al. 2012; Stier et al. 2014; Pauliny et al. 2015; Ringsby et al. 2015; Vedder et al. 2017, 2018). A quicker post-hatching growth ensures a higher success rate at fledging (Kersten and Brenninkmeijer 1995; Harris et al. 2008; Canestrari et al. 2011; Loock et al. 2017; Hipfner and Gaston 1999) and an earlier fledging date may decrease predation risk in sociable weavers (Ferreira 2015). As a result, there could be a stronger evolutionary pressure on body growth rather than telomere length; in other words, short-term survival by avoiding predation rather than long-term survival through somatic maintenance. Alternatively, resource-investment trade-offs may be reflected not in body condition or mass, but in tissue maturation rate, which could be reflected in shorter telomeres (Criscuolo et al. 2019).

\section{Conclusions}

Here, we set to investigate the effect of the social environment (presence of helpers) before and after hatching on offspring rTL. Our results suggest an overall positive effect of postnatal helpers on the offspring rTL early in life, but our study did not provide evidence that this relationship is conserved until fledging. Furthermore, the positive postnatal effect of helper presence was dependent on prenatal conditions, being stronger in nests that did not have pre-natal helpers. Thus, the presence of helpers may induce opposite effects depending on whether helpers are present before or after hatching and that the interaction between the prenatal and postnatal environment is essential to understand the consequences of the social environment on offspring. In addition to the social environment, the ecological context (e.g., temperature, food availability) may also affect rTL, both before and after hatching, but this was not investigated here. This calls for data over longer periods spanning different climatic conditions, to decipher the interaction between social and ecological environment. According to our results, the chicks with the shortest telomeres in their early life might also be less likely to survive the first years of life. Although other factors influence rTL, such as genetics or the quality of care provided, our study suggests that social context, has a potential important role to play in influencing individual development and survival in cooperatively breeding birds. However, the mechanisms that sustain these pre- and post-natal social effects on rTL remain to be identified and further studies
768 
on the underlying molecular mechanisms (e.g. hormones, oxidative stress, metabolic pathways) are now needed.

Supplementary Information The online version contains supplementary material available at https://doi.org/10.1007/s00442-021-04917-8.

Acknowledgements Data collection would have not been possible without the contribution of several people working in the field, in particular, Max Loubon, Margaux Rat, Lara Broom, and all the students and volunteers that contributed to the annual sociable weaver captures. We thank Sophie Lardy for the helpful discussion regarding the study design and analysis, and two reviewers for relevant and helpful comments. De Beers Consolidated Mines permitted us to work at Benfontein Reserve.

Author contribution statement $\mathrm{BF}, \mathrm{CD}, \mathrm{MP}$ and $\mathrm{RC}$ designed the study. CD, FT, MP and RC collected the data in the field. CD, FT, MP, MQ and RC organized the database. MQ performed the statistical analysis, MP the survival analysis and SZ the laboratory analyses. MQ wrote the first draft of the manuscript. CD, CS, FC, MP, RC and SZ wrote sections of the manuscript. All authors contributed to manuscript revision, read and approved the submitted version.

Funding The sociable weaver project and the present study have been supported by funding from the FitzPatrick Institute of African Ornithology (DST-NRF Centre of Excellence) at the University of Cape Town (South Africa), the European program Marie Curie-IRSES (FP7-PEOPLE-2012-IRSES; 'Cooperation' 318994), FCT (Portugal) through grants IF/01411/2014/CP1256/CT0007 and PTDC/ BIA-EVF/5249/2014 to RC and ANR (France) through Project ANR15-CE32-0012-02 to CD. This work was conducted under the CNRSCIBIO Laboratoire International Associé (LIA) and the OSU OREME.

\section{Declarations}

Conflict of interest The authors declare that the research was conducted in the absence of any commercial or financial relationships that could be construed as a potential conflict of interest.

\section{References}

Arnold KE, Owens IPF (1998) Cooperative breeding in birds: a comparative test of the life history hypothesis. Proc R Soc Lond B Biol Sci 265:739-745

Barrett ELB, Richardson DS (2011) Sex differences in telomeres and lifespan. Aging Cell 10:913-921

Barrett ELB, Burke TA, Hammers M et al (2013) Telomere length and dynamics predict mortality in a wild longitudinal study. Mol Ecol 22:249-259

Bartoń K (2013) MuMIn: multi-model inference. R package version 1 Beaulieu M, Reichert S, Maho YL et al (2011) Oxidative status and telomere length in a long-lived bird facing a costly reproductive event. Funct Ecol 25:577-585

Bebbington K, Fairfield EA, Spurgin LG et al (2018) Joint care can outweigh costs of nonkin competition in communal breeders. Behav Ecol 29:169-178

Bize P, Roulin A, Richner H (2002) Covariation between egg size and rearing condition determines offspring quality: an experiment with the alpine swift. Oecologia 132:231-234

Bize P, Criscuolo F, Metcalfe NB et al (2009) Telomere dynamics rather than age predict life expectancy in the wild. Proc R Soc Lond B Biol Sci 276:1679-1683
Boonekamp JJ, Mulder GA, Salomons HM et al (2014) Nestling telomere shortening, but not telomere length, reflects developmental stress and predicts survival in wild birds. Proc R Soc Lond B Biol Sci 281:20133287

Brouwer L, Richardson DS, Komdeur J (2012) Helpers at the nest improve late-life offspring performance: evidence from a longterm study and a cross-foster experiment. PLoS ONE 7:e33167

Canestrari D, Marcos JM, Baglione V (2011) Helpers at the nest compensate for reduced maternal investment in egg size in carrion crows. J Evol Biol 24:1870-1878

Caprioli M, Romano M, Romano A et al (2013) Nestling telomere length does not predict longevity, but covaries with adult body size in wild barn swallows. Biol Lett 9:20130340

Cawthon RM (2002) Telomere measurement by quantitative PCR. Nucleic Acids Res 30:e47-e47

Chatelain M, Drobniak SM, Szulkin M (2020) The association between stressors and telomeres in non-human vertebrates: a meta-analysis. Ecol Lett 23:381-398

Clarke MF (1984) Cooperative breeding by the Australian bell miner Manorina melanophrys Latham: a test of kin selection theory. Behav Ecol Sociobiol 14:137-146

Clutton-Brock TH, Russell AF, Sharpe LL et al (2001) Effects of helpers on juvenile development and survival in meerkats. Science 293:2446-2449

Cockburn A (1998) Evolution of helping behavior in cooperatively breeding birds. Annu Rev Ecol Syst 29:141-177

Costanzo A, Parolini M, Bazzi G et al (2017) Brood size, telomere length, and parent-offspring color signaling in barn swallows. Behav Ecol 28:204-211

Covas R (2012) The benefits of long-term studies: 16 year old sociable weaver caught at Benfontein Game Reserve. Afring News 41:11-12

Covas R, Dalecky A, Caizergues A, Doutrelant C (2006) Kin associations and direct vs indirect fitness benefits in colonial cooperatively breeding sociable weavers Philetairus socius. Behav Ecol Sociobiol 60:323-331

Covas R, du Plessis MA, Doutrelant C (2008) Helpers in colonial cooperatively breeding sociable weavers Philetairus socius contribute to buffer the effects of adverse breeding conditions. Behav Ecol Sociobiol 63:103-112

Covas R, Deville A-S, Doutrelant C et al (2011) The effect of helpers on the postfledging period in a cooperatively breeding bird, the sociable weaver. Anim Behav 81:121-126

Crick HQP (1992) Load-lightening in cooperatively breeding birds and the cost of reproduction. Ibis 134:56-61

Criscuolo F, Bize P, Nasir L et al (2009) Real-time quantitative PCR assay for measurement of avian telomeres. J Avian Biol 40:342-347

Criscuolo F, Cornell A, Zahn S, Williams TD (2019) Oxidative status and telomere length are related to somatic and physiological maturation in chicks of European starlings (Sturnus vulgaris). J Exp Biol 222:jeb204719

de Loock DV, Strubbe D, Neve LD et al (2017) Cooperative breeding shapes post-fledging survival in an Afrotropical forest bird. Ecol Evol 7:3489-3493

Dixit T, English S, Lukas D (2017) The relationship between egg size and helper number in cooperative breeders: a meta-analysis across species. PeerJ 5:16

Doerr ED, Doerr VAJ (2007) Positive effects of helpers on reproductive success in the brown treecreeper and the general importance of future benefits. J Anim Ecol 76:966-976

Doutrelant C, Covas R, Caizergues A, Du Plessis M (2004) Unexpected sex ratio adjustment in a colonial cooperative bird: pairs with helpers produce more of the helping sex whereas pairs without helpers do not. Behav Ecol Sociobiol 56:149-154 
Downing PA, Cornwallis CK, Griffin AS (2015) Sex, long life and the evolutionary transition to cooperative breeding in birds. Proc $\mathrm{R}$ Soc B Biol Sci 282:20151663

Drent RH, Daan S (2002) The prudent parent: energetic adjustments in avian breeding. Ardea 38-90:225-252

Dugdale HL, Richardson DS (2018) Heritability of telomere variation: it is all about the environment! Philos Trans R Soc B Biol Sci 373:20160450

Eastwood JR, Hall ML, Teunissen N et al (2019) Early-life telomere length predicts lifespan and lifetime reproductive success in a wild bird. Mol Ecol 28:1127-1137

Eisenberg DTA (2016) Telomere length measurement validity: the coefficient of variation is invalid and cannot be used to compare quantitative polymerase chain reaction and Southern blot telomere length measurement techniques. Int J Epidemiol 45:1295

Entringer S, Epel ES, Kumsta R et al (2011) Stress exposure in intrauterine life is associated with shorter telomere length in young adulthood. Proc Natl Acad Sci 108:E513-E518

Ferreira AMC (2015) Benefits and costs of helpers: investigating the underlying mechanisms

Fortuna R, Paquet M, Ferreira AC et al. (2021) Maternal allocation in relation to weather, predation and social factors in a colonial cooperative bird. J Anim Ecol.

Fox CW, Thakar MS, Mousseau TA (1997) Egg size plasticity in a seed beetle: an adaptive maternal effect. Am Nat 149:149-163

Geiger S, Vaillant ML, Lebard T et al (2012) Catching-up but telomere loss: half-opening the black box of growth and ageing trade-off in wild king penguin chicks. Mol Ecol 21:1500-1510

Gelman A, Rubin DB (1992) Inference from iterative simulation using multiple sequences. Stat Sci 7:457-472

Ghalambor CK, Martin TE (2001) Fecundity-survival trade-offs and parental risk-taking in birds. Science 292:494-497

Gimenez O, Rossi V, Choquet R et al (2007) State-space modelling of data on marked individuals. Ecol Model 206:431-438

Gimenez O, Viallefont A, Charmantier A et al (2008) The risk of flawed inference in evolutionary studies when detectability is less than one. Am Nat 172:441-448

Groothuis TGG, Hsu B-Y, Kumar N, Tschirren B (2019) Revisiting mechanisms and functions of prenatal hormone-mediated maternal effects using avian species as a model. Philos Trans R Soc B Biol Sci 374:20180115

Hall ME, Nasir L, Daunt F et al (2004) Telomere loss in relation to age and early environment in long-lived birds. Proc R Soc Lond B Biol Sci 271:1571-1576

Hammers M, Kingma SA, Spurgin LG et al (2019) Breeders that receive help age more slowly in a cooperatively breeding bird. Nat Commun 10:1301

Harris MP, Halley DJ, Wanless S (2008) The post-fledging survival of young Guillemots Uria aalge in relation to hatching date and growth. Ibis 134:335-339

Harrison XA, Donaldson L, Correa-Cano ME et al (2018) A brief introduction to mixed effects modelling and multi-model inference in ecology. PeerJ 6:e4794

Haussmann MF, Longenecker AS, Marchetto NM et al (2012) Embryonic exposure to corticosterone modifies the juvenile stress response, oxidative stress and telomere length. Proc R Soc B Biol Sci 279:1447

Heidinger BJ, Blount JD, Boner W et al (2012) Telomere length in early life predicts lifespan. Proc Natl Acad Sci 109:1743-1748

Herborn KA, Heidinger BJ, Boner W et al (2014) Stress exposure in early post-natal life reduces telomere length: an experimental demonstration in a long-lived seabird. Proc R Soc B Biol Sci 281:20133151

Hipfner JM, Gaston AJ (1999) The relationship between egg size and posthatching development in the thick-billed murre. Ecology 80:1289-1297
Hothorn T, Bretz F, Westfall P (2008) Simultaneous inference in general parametric models. Biom J 50:346-363

Hunter LA (1987) Cooperative breeding in purple gallinules: the role of helpers in feeding chicks. Behav Ecol Sociobiol 20:171-177

Ingles ED, Deakin JE (2016) Telomeres, species differences, and unusual telomeres in vertebrates: presenting challenges and opportunities to understanding telomere dynamics. Genet 3:1-24

Kersten M, Brenninkmeijer A (1995) Growth, fledging success and post-fledging survival of juvenile Oystercatchers Haematopus ostralegus. Ibis 137:396-404

Kingma SA, Hall ML, Arriero E, Peters A (2010) Multiple benefits of cooperative breeding in purple-crowned fairy-wrens: a consequence of fidelity? J Anim Ecol 79:757-768

Krist M (2011) Egg size and offspring quality: a meta-analysis in birds. Biol Rev 86:692-716

Lai T-P, Wright WE, Shay JW (2018) Comparison of telomere length measurement methods. Phil Trans R Soc B 373:20160451

Langmore NE, Bailey LD, Heinsohn RG et al (2016) Egg size investment in superb fairy-wrens: helper effects are modulated by climate. Proc R Soc B Biol Sci 283:20161875

Lejeune L, van de Pol M, Cockburn A et al (2016) Male and female helper effects on maternal investment and adult survival in redwinged fairy-wrens. Behav Ecol 27:1841-1850

Maclean GL (1973a) The sociable weaver, part 2: nest architecture and social organization. Ostrich 44:191-218

Maclean GL (1973b) The sociable weaver, part 5: food, feeding and general behaviour. Ostrich 44:254-261

Meillère A, Brischoux F, Ribout C, Angelier F (2015) Traffic noise exposure affects telomere length in nestling house sparrows. Biol Lett 11:20150559

Mizutani Y, Tomita N, Niizuma Y, Yoda K (2013) Environmental perturbations influence telomere dynamics in long-lived birds in their natural habitat. Biol Lett 9:20130511

Mizutani Y, Niizuma Y, Yoda K (2016) How do growth and sibling competition affect telomere dynamics in the first month of life of long-lived seabird? (JM Avilés, Ed). PLoS ONE 11:e0167261

Monaghan P and Ozanne SE. 2018. Somatic growth and telomere dynamics in vertebrates: relationships, mechanisms and consequences. Philos Trans R Soc Lond B Biol Sci 373.

Morrison ES, Ardia DR, Clotfelter ED (2009) Cross-fostering reveals sources of variation in innate immunity and hematocrit in nestling tree swallows Tachycineta bicolor. J Avian Biol 40:573-578

Nettle D, Monaghan P, Gillespie R et al (2015) An experimental demonstration that early-life competitive disadvantage accelerates telomere loss. Proc R Soc Lond B Biol Sci 282:20141610

Noguera JC, Velando A (2019) Reduced telomere length in embryos exposed to predator cues. J Exp Biol 222:jeb216176

Noguera JC, Velando A (2020) Gull chicks grow faster but lose telomeres when prenatal cues mismatch the real presence of sibling competitors. Proc R Soc B Biol Sci 287:20200242

Nussey DH, Baird D, Barrett E et al (2014) Measuring telomere length and telomere dynamics in evolutionary biology and ecology. Methods Ecol Evol 5:299-310

Paquet M, Covas R, Chastel O et al (2013) Maternal effects in relation to helper presence in the cooperatively breeding sociable weaver. PLoS ONE 8:e59336

Paquet M, Covas R, Doutrelant C (2015a) A cross-fostering experiment reveals that prenatal environment affects begging behaviour in a cooperative breeder. Anim Behav 102:251-258

Paquet M, Doutrelant C, Hatchwell BJ et al (2015b) Antagonistic effect of helpers on breeding male and female survival in a cooperatively breeding bird. J Anim Ecol 84:1354-1362

Paquet M, Doutrelant C, Loubon M et al (2016) Communal roosting, thermoregulatory benefits and breeding group size predictability in cooperatively breeding sociable weavers. J Avian Biol 47:749-755 
Pauliny A, Wagner RH, Augustin J et al (2006) Age-independent telomere length predicts fitness in two bird Species. Mol Ecol 15:1681-1687

Pauliny A, Devlin RH, Johnsson JI, Blomqvist D (2015) Rapid growth accelerates telomere attrition in a transgenic fish. BMC Evol Biol 15:159

Pfaffl MW (2001) A new mathematical model for relative quantification in real-time RT-PCR. Nucleic Acids Res 29:e45-e45

Plummer M (2013) rjags: Bayesian graphical models using MCMC. $\mathrm{R}$ package version 3 .

Plummer M (2015) JAGS Version 4.0. 0 user manual. See Httpssourceforgenetprojectsmcmc-JagsfilesManuals4x.

Preston SAJ, Briskie JV, Hatchwell BJ (2016) Adult helpers increase the recruitment of closely related offspring in the cooperatively breeding rifleman. Behav Ecol 27:1617-1626

R Core Team (2019) R: a language and environment for statistical computing. R Foundation for Statistical Computing, Vienna, Austria

Reichert S, Stier A, Zahn S et al (2014) Increased brood size leads to persistent eroded telomeres. Front Ecol Evol 2:9

Reichert S, Froy H, Boner W et al (2017) Telomere length measurement by qPCR in birds is affected by storage method of blood samples. Oecologia 184:341-350

Reid JM, Bignal EM, Bignal S et al (2003) Age-specific reproductive performance in red-billed choughs Pyrrhocorax pyrrhocorax: patterns and processes in a natural population. J Anim Ecol 72:765-776

Ridley AR (2007) Factors affecting offspring survival and development in a cooperative bird: social, maternal and environmental effects. J Anim Ecol 76:750-760

Ringsby TH, Jensen H, Pärn H et al (2015) On being the right size: increased body size is associated with reduced telomere length under natural conditions. Proc R Soc B 282:20152331

Russell AF, Lummaa V (2009) Maternal effects in cooperative breeders: from hymenopterans to humans. Philos Trans R Soc B Biol Sci 364:1143-1167

Russell AF, Langmore NE, Cockburn A et al (2007) Reduced egg investment can conceal helper effects in cooperatively breeding birds. Science 317:941-944

Russell AF, Langmore NE, Gardner JL, Kilner RM (2008) Maternal investment tactics in superb fairy-wrens. Proc R Soc B Biol Sci 275:29-36

Salmón P, Nilsson JF, Nord A et al (2016) Urban environment shortens telomere length in nestling great tits Parus major. Biol Lett 12:20160155

Salomons HM, Mulder GA, van de Zande L et al (2009) Telomere shortening and survival in free-living corvids. Proc R Soc B Biol Sci 276:3157-3165

Santos ESA, Macedo RH (2011) Load lightening in southern lapwings: group-living mothers lay smaller eggs than pair-living mothers. Ethology 117:547-555

Sappington J (1977) Breeding biology of house sparrows in North Mississippi. Wilson Bull 89:300-309

Smith S, Turbill C, Penn DJ (2011) Chasing telomeres, not red herrings, in evolutionary ecology. Heredity 107:372-373

Spurgin LG, Bebbington K, Fairfield EA et al (2017) Spatio-temporal variation in lifelong telomere dynamics in a long-term ecological study. J Anim Ecol 87:187

Stearns SC (1977) The evolution of life history traits: a critique of the theory and a review of the data. Annu Rev Ecol Syst 8:145-171

Stier A, Viblanc VA, Massemin-Challet S et al (2014) Starting with a handicap: phenotypic differences between early- and late-born king penguin chicks and their survival correlates (D Costa, Ed). Funct Ecol 28:601-611

Stier A, Metcalfe NB, Monaghan P (2020) Pace and stability of embryonic development affect telomere dynamics: an experimental study in a precocial bird model. Proc R Soc B Biol Sci 287:20201378

Taborsky B (2006) Mothers determine offspring size in response to own juvenile growth conditions. Biol Lett 2:225-228

Tanaka H, Kohda M, Frommen JG (2018) Helpers increase the reproductive success of breeders in the cooperatively breeding cichlid Neolamprologus obscurus. Behav Ecol Sociobiol 72:152

Tarry-Adkins JL, Chen JH, Smith NS et al (2009) Poor maternal nutrition followed by accelerated postnatal growth leads to telomere shortening and increased markers of cell senescence in rat islets. FASEB J 23:1521-1528

Tchkonia T, Zhu Y, van Deursen J et al (2013) Cellular senescence and the senescent secretory phenotype: therapeutic opportunities. J Clin Invest 123:966-972

van Dijk RE, Covas R, Doutrelant C et al (2015) Fine-scale genetic structure reflects sex-specific dispersal strategies in a population of sociable weavers (Philetairus socius). Mol Ecol 24:4296-4311

van Lieshout SHJ, Bretman A, Newman C et al (2019) Individual variation in early-life telomere length and survival in a wild mammal. Mol Ecol 28:4152-4165

Vedder O, Verhulst S, Bauch C, Bouwhuis S (2017) Telomere attrition and growth: a life-history framework and case study in common terns. J Evol Biol 30:1409-1419

Vedder O, Verhulst S, Zuidersma E, Bouwhuis S (2018) Embryonic growth rate affects telomere attrition: an experiment in a wild bird. J Exp Biol 221:jeb181586

Velando A, Torres R, Espinosa I (2005) Male coloration and chick condition in blue-footed booby: a cross-fostering experiment. Behav Ecol Sociobiol 58:175-180

Vijendravarma RK, Narasimha S, Kawecki TJ (2010) Effects of parental larval diet on egg size and offspring traits in Drosophila. Biol Lett 6:238-241

Voillemot M, Hine K, Zahn S et al (2012) Effects of brood size manipulation and common origin on phenotype and telomere length in nestling collared flycatchers. BMC Ecol 12:17

Weber BM, Bowers EK, Terrell KA et al (2018) Pre- and postnatal effects of experimentally manipulated maternal corticosterone on growth, stress reactivity and survival of nestling house wrens. Funct Ecol 32:1995-2007

Wilbourn RV, Moatt JP, Froy H et al (2018) The relationship between telomere length and mortality risk in non-model vertebrate systems: a meta-analysis. Philos Trans R Soc B Biol Sci 373:20160447

Wilkinson R, Brown AE (1984) Effect of helpers on the feeding rates of nestlings in the chestnut-bellied starling Spreo pulcher. J Anim Ecol 53:301-310

Wood E (2017) Causes and fitness consequences of telomere dynamics in a wild social bird.

Wood EM, Young AJ (2019) Telomere attrition predicts reduced survival in a wild social bird, but short telomeres do not. Mol Ecol 28:3669-3680

Young RC, Kitaysky AS, Haussmann MF et al (2013) Age, sex, and telomere dynamics in a long-lived seabird with male-biased parental care. PLoS ONE 8:e74931

Young RC, Welcker J, Barger CP et al (2017) Effects of developmental conditions on growth, stress and telomeres in black-legged kittiwake chicks. Mol Ecol 26:3572-3584
1108

1109

1110

1111

1112

1113

1114

1115

1116

1117

1118

1119

1120

1121

1122

1123

1124

1125

1126

1127

1128

1129

1130

1131

1132

1133

1134

1135

1136

1137

1138

1139

1140

1141

1142

1143

1144

1145

1146

1147

1148

1149

1150

1151

1152

1153

1154

1155

1156

1157

AQ11 9

1160

1161

1162

1163

1164

1165

1166

1167

1168 


\begin{tabular}{ll|}
\hline Journal: & $\mathbf{4 4 2}$ \\
Article: & $\mathbf{4 9 1 7}$
\end{tabular}

\section{Author Query Form}

\section{Please ensure you fill out your response to the queries raised below and return this form along with your corrections}

Dear Author

During the process of typesetting your article, the following queries have arisen. Please check your typeset proof carefully against the queries listed below and mark the necessary changes either directly on the proof/online grid or in the 'Author's response' area provided below

\begin{tabular}{|l|l|l|}
\hline Query & Details Required & Author's Response \\
\hline AQ1 & $\begin{array}{l}\text { Kindly check and confirm the updated city names in affiliations [1,3, 7,6] and country } \\
\text { name in affiliation [5] are correct. }\end{array}$ & \\
\hline AQ2 & Kindly check and confirm the affiliation [7] is correctly identified. & \\
\hline AQ3 & $\begin{array}{l}\text { Reference: Reference (Covas 2011) was mentioned in the manuscript; however, this } \\
\text { was not included in the reference list. As a rule, all mentioned references should be } \\
\text { present in the reference list. Please provide the reference details to be inserted in the } \\
\text { reference list. }\end{array}$ & \\
\hline AQ4 & Please provide a definition for the significance of [bold] in the tables 2, 3. & \\
\hline AQ5 & Please confirm the section headings are correctly identified. & \\
\hline AQ6 & $\begin{array}{l}\text { Kindly check and confirm the updated page number are correct in references } \\
\text { [Criscuolo et al. 2019, Nettle et al. 2015, Noguera and Velando 2019, Reichert et al. }\end{array}$ & \\
\hline AQ7 & $\begin{array}{l}\text { Kindly check and confirm the updated volume and page number are correct in } \\
\text { references [Eisenberg 2016, Haussmann et al. 2012, Spurgin et al. 2017]. }\end{array}$ & \\
\hline AQ8 & Please provide volume number, page number/DOI for reference [Fortuna et al. 2021]. & \\
\hline AQ9 & $\begin{array}{l}\text { Kindly check and confirm the updated volume number is correct in reference [Gelman } \\
\text { and Rubin 1992]. }\end{array}$ & \\
\hline AQ10 & $\begin{array}{l}\text { Kindly check and confirm the updated year in reference [Hipfner and Gaston 1999] is } \\
\text { correct. }\end{array}$ & \\
\hline AQ11 & Please provide full details for references [Ferreira 2015, Wood 2017]. & \\
\hline
\end{tabular}

\begin{tabular}{|l|l|l|l|l|}
\hline Journal : Large 442 & Article No : 4917 & Pages : 1 & MS Code : 4917 & Dispatch : 12-4-2021 \\
\hline
\end{tabular}

